\title{
Oxygen desaturation during a 6-min walk identifies a COPD phenotype with an increased risk of morbidity and mortality
}

\author{
Paul L. Enright \\ Affiliation: Respiratory Science Center, University of Arizona, Mount Lemmon, AZ, USA. \\ Correspondence: Paul L. Enright, Respiratory Science Center, University of Arizona, PO Box 675, Mount \\ Lemmon, AZ, USA. E-mail: lungguydagmail.com
}

○ @ERSpublications

6MWD: patients who desaturate have higher morbidity/mortality rates when compared with those who do not desaturate http://ow.ly/J63B3006JCg

M. Waatevik and co-investigators from Bergen, Norway, have added to the evidence that smokers with airflow limitation who have oxygen desaturation during a 6-min walk test (6MWT) are: $50 \%$ more likely to have respiratory exacerbations; more rapidly lose lung function; and have twice the mortality rate when compared with patients who do not desaturate [1]. Uniquely, they also found that "desaturators" were much more likely to become cachectic (lose fat-free body mass) during follow-up.

I suspect that desaturation during exercise was an index of the emphysema phenotype of chronic obstructive pulmonary disease (COPD) and/or heart failure. Indices of emphysema in smokers include a low diffusing capacity of the lung for carbon monoxide and hyperlucency on lung high-resolution computed tomography, both of which predict higher morbidity and mortality in smokers with COPD $[2,3]$. Due to a common aetiology (smoking), heart failure and other cardiovascular diseases commonly coexist with COPD [4]. Heart failure also causes dyspnoea and/or oxygen desaturation on exertion; also causes cachexia; also causes a rapid decline in lung function; and drives all-cause mortality in patients with COPD [5]. It is unfortunate that heart failure is often overlooked by pulmonary sub-specialists because the treatments for heart failure are much more effective for reducing morbidity and mortality than are the treatments for COPD. Therefore, every older patient with a "COPD" or asthma exacerbation should have an inexpensive B-type natriuretic peptide blood test to rule out (or detect) heart failure $[6,7]$.

The 2002 American Thoracic Society guidelines (ATS) for the 6MWT [8] stated that measuring oxygen saturation during the test was optional. However, a combined European Respiratory Society and ATS working group recently provided an update [9] and carefully examined the evidence for the clinical usefulness of "field walking tests" [10]. The new guideline states that "desaturation during a 6MWT provides information regarding disease severity and prognosis in COPD, interstitial lung disease, pulmonary arterial hypertension, and systemic sclerosis patients with pulmonary manifestations. Desaturation during the 6MWT has been associated with more severe lung disease, higher levels of dyspnoea, poorer muscle strength, impaired daily physical activity and desaturation during daily life activities across a range of chronic respiratory diseases." The 6MWT is more sensitive for identifying exercise-induced desaturation than exercise testing using a cycle ergometer [11].

More than half of patients with moderate-to-severe lung disease have oxygen desaturation of $>4 \%$ during the test. The nadir of arterial oxygen saturation measured by pulse oximetry $\left(\mathrm{SpO}_{2}\right)$ may occur before the end of the 6MWT, so the $\mathrm{SpO}_{2}$ and pulse should be recorded for a few minutes before the test, throughout the test, and during the recovery period [12]. Pulse oximeters are available that record continuously with printing of the trends of pulse and saturation after the test is completed. Alternatives include an assessor

Received: May 032016 | Accepted: May 042016

Conflict of interest: None declared.

Copyright OERS 2016 
walking behind the patient and watching the oximeter display (worn on a belt) or use of an oximeter which continuously sends the results to a recording device via Bluetooth technology. However, there is no need to monitor $\mathrm{SpO}_{2}$ during the test for safety. Even with modern oximeters, I have seen motion artefact cause falsely low $\mathrm{SpO}_{2}$ readings (unaccompanied by an increasing heart rate), so it is worthwhile for quality assurance to review the trends before interpreting the numbers. Problems obtaining accurate oximetry values are more common in patients with systemic sclerosis (due to poor perfusion in fingers).

A common problem implementing the $6 \mathrm{MWT}$ in clinical settings is the $30 \mathrm{~m}$ track length (a very long hallway) used by the investigators who provided reference equations for the 6MWT distance [10, 13]. Reducing the length between traffic cones from 30 to $10 \mathrm{~m}$ reduces the average 6MWT distance by about $10 \%$, since patients must slow down to make more frequent turns [14], but this factor is not significant for patients with severe lung disease [15] and the shorter track length probably does not influence the degree of desaturation recorded.

In summary, after a review of the new guidelines, it's time for you to purchase a couple of small orange traffic cones, a lap counter, and a recording pulse oximeter to measure both the 6MWT distance and the degree of oxygen desaturation during the short walk for many of your patients. The initial test results will help you to determine disease severity, quality of life, COPD phenotype, and prognosis. The results during follow-up visits will provide an objective measure of response to therapy.

\section{References}

1 Waatevik M, Johannessen A, Gomez Real F, et al. Oxygen desaturation in 6-min walk test is a risk factor for adverse outcomes in COPD. Eur Respir J 2016; 48: 82-91.

2 Farkhooy A, Janson C, Arnardóttir RH. Impaired carbon monoxide diffusing capacity is the strongest lung function predictor of decline in 12 minute-walking distance in COPD; a 5-year follow-up study. COPD 2015; 12 : 243-251.

3 Nishimura M, Makita $\mathrm{H}$, Nagai $\mathrm{K}$, et al. Annual change in pulmonary function and clinical phenotype in chronic obstructive pulmonary disease. Am J Respir Crit Care Med 2012; 185: 44-52.

4 Chen W, Thomas J, Sadatsafavi M, et al. Risk of cardiovascular comorbidity in patients with chronic obstructive pulmonary disease: a systematic review and meta-analysis. Lancet Respir Med 2015; 3: 631-639.

5 Hawkins NM, Petrie MC, Jhund PS, et al. Heart failure and chronic obstructive pulmonary disease: diagnostic pitfalls and epidemiology. Eur J Heart Failure 2009; 11: 130-139.

6 McCullough PA, Hollander JE, Nowak RM, et al. Uncovering heart failure in patients with a history of pulmonary disease: rationale for the early use of B-type natriuretic peptide in the emergency department. Acad Emerg Med 2003; 10: 198-204.

7 Rutten FH, Cramer MJ, Zuithoff NP, et al. Comparison of B-type natriuretic peptide assays for identifying heart failure in stable elderly patients with a clinical diagnosis of chronic obstructive pulmonary disease. Eur J Heart Failure 2007; 9: 651-659.

8 ATS Statement: guidelines for the six minute walk test. Am J Respir Crit Care Med 2002; 166: 111-117.

9 Holland AE, Spruit MA, Troosters T, et al. An official European Respiratory Society/American Thoracic Society technical standard: field walking tests in chronic respiratory disease. Eur Respir J 2014; 44: 1428-1446.

10 Singh SJ, Puhan MA, Andrianopoulos V, et al. An official systematic review of the European Respiratory Society/ American Thoracic Society: measurement properties of field walking tests in chronic respiratory disease. Eur Respir J 2014; 44: 1447-1478.

11 Poulain M, Durand F, Palomba B, et al. 6-minute walk testing is more sensitive than maximal incremental cycle testing for detecting oxygen desaturation in patients with COPD. Chest 2003; 123: 1401-1407.

12 Fiore C, Lee A, McDonald C, et al. Should oxyhaemoglobin saturation be monitored continuously during the 6-minute walk test? Chron Respir Dis 2011; 8: 181-184.

13 Casanova C, Celli BR, Barria P, et al. The 6-min walk distance in healthy subjects: reference standards from seven countries. Eur Respir J 2011; 37: 150-156.

14 Beekman E, Mesters I, Hendriks EJ, et al. Course length of 30 metres versus 10 metres has a significant influence on six-minute walk distance in patients with COPD: an experimental crossover study. J Physiother 2013; 59: 169-176.

15 Sciurba F, Criner GJ, Lee SM, et al. Six-minute walk distance in chronic obstructive pulmonary disease: reproducibility and effect of walking course layout and length. Am J Respir Crit Care Med 2003; 167: 1522-1527. 